\title{
Short Communication: New Alleles of the Bovine k-Casein Gene Revealed by Resequencing and Haplotype Inference Analysis
}

\author{
S. Y. Chen, ${ }^{*}$ V. Costa, ${ }^{*}$ M. Azevedo, ${ }^{*}$ M. Baig,† N. Malmakov, $\ddagger$ G. Luikart, ${ }^{*}$ G. Erhardt, $§$ and A. Beja-Pereira* \\ ${ }^{*}$ Centro de Investigação em Biodiversidade e Recursos Genéticos (CIBIO), Universidade do Porto, Campus Agrário de Vairão, 4485-661 Vairão, \\ Portugal \\ †Department of Zoology, Government Vidarbha Institute of Science and Humanities, Amravati, India \\ ¥Reproduction Laboratory, Research Center of Sheep Breeding, Mynbaevo village, Almaty Oblast, 040622 Kazakhstan \\ §Institute of Animal Breeding and Genetics, Justus-Liebig University, 35390 Giessen, Germany
}

\section{ABSTRACT}

We tested the hypothesis that extensive undiscovered genetic diversity exists in important functional genes from domestic and wild cattle species (Bos spp.). We resequenced $483 \mathrm{bp}$ of a key exon (exon IV) from the kappa (к)-casein gene (CSN3) for a panel of samples of domestic cattle from 8 countries and a close relative species, the gayal (Bos frontalis). Six single nucleotide polymorphisms were identified. Haplotype inference revealed 12 haplotypes, of which 8 were newly discovered. Among these 8 new haplotypes, 5 differed by one nonsynonymous mutation and 3 differed by one silent mutation from previously well-characterized CSN3 alleles. From those, one was shared by the gayal and Zebu, was different from $C S N 3^{*} B$ at position Ile $136 \mathrm{Thr}$, and showed a close phylogenetic relationship with the banteng, gaur, and yak. The other 7 new haplotypes were detected in our panel of worldwide local cattle breeds but were absent from previously reported commercial breeds. These results support the hypothesis that genetic diversity at the coding region of CSN3 has been underestimated. This study also highlights how important it is to resequence functionally important genes in worldwide local cattle breeds, many of which are threatened by extinction or replacement by commercial breeds.

Key words: $\mathrm{k}$-casein, single nucleotide polymorphism, haplotype inference

The bovine $\mathrm{k}$-casein protein plays an important role in cheese production technology (e.g., stabilization of casein micelles), and in physiological processes such as cytotoxic and antibacterial activities important for disease resistance (Dziuba and Minkiewicz, 1996; Matin and Otani, 2002). For example, previous studies demonstrated that genetic variants $\mathrm{A}$ and $\mathrm{B}$ of this protein

Received March 29, 2008.

Accepted May 26, 2008.

${ }^{1}$ Corresponding author: albanobp@fc.up.pt show different biological activities (e.g., Yvon et al., 1994) and are associated with milk production traits (e.g., Ng-Kwai-Hang et al., 1984). Because different variants of this protein might have different functional activities or associations with milk yield traits, it is of longstanding interest to identify and characterize the diversity harbored in the $\mathrm{k}$-casein gene (CSN3) in the bovine species (Bos spp.).

Until now, researchers have reported 10 well-characterized genetic variants $\left(A, A^{1}, B, C, E, F, G, H, I\right.$, and $J$ ) in domestic cattle (Bos taurus and Bos indicus) (Prinzenberg et al., 2008) and 4 genetic variants found in the domestic yak (Bos grunniens; Bai et al., 2008; Prinzenberg et al., 2008). So far, most of these variants have been genotyped by using PCR-single strand conformation polymorphism analyses (e.g., Prinzenberg et al., 1999, 2008). This routine genotyping system is costeffective and sufficiently sensitive for both the genotyping of known mutations and the detection of new mutations in DNA fragments. However, its efficiency is poor for detecting sequence variation for larger DNA fragments (e.g., >300 bp; Sheffield et al., 1993; Jaeckel et al., 1998).

Characterization of variation in functional genes (such as the milk protein genes) with potentially adaptive variation is increasingly urgent because numerous local breeds and wild relative taxa are being lost at an accelerating rate (Food and Agriculture Organization of the United Nations, 2007). However, most studies on functional genes include only a few selected cattle breeds from Europe (Prinzenberg et al., 1999). Apart from the few studies in the most widely distributed breeds of $B$. indicus (e.g., Sahiwal, Gir), there is a great lack of information on genetic diversity in native Asiatic cattle at functional important genes, such as the CSN3. For example, the few existing reports on the genetic diversity of $C S N 3$ in native Asiatic cattle were limited to the genotyping of the major genetic variants (alleles A and B) by using techniques such as PCRRFLP, which does not allow detection of new variants (Mitra et al., 1998). Thus, it is important to screen for 
Table 1. Observed genotypes (G01 to G13) with their distribution and inferred haplotypes (H01 to H12) with estimated frequencies (confidence interval probability 0.97 to $1.00)$

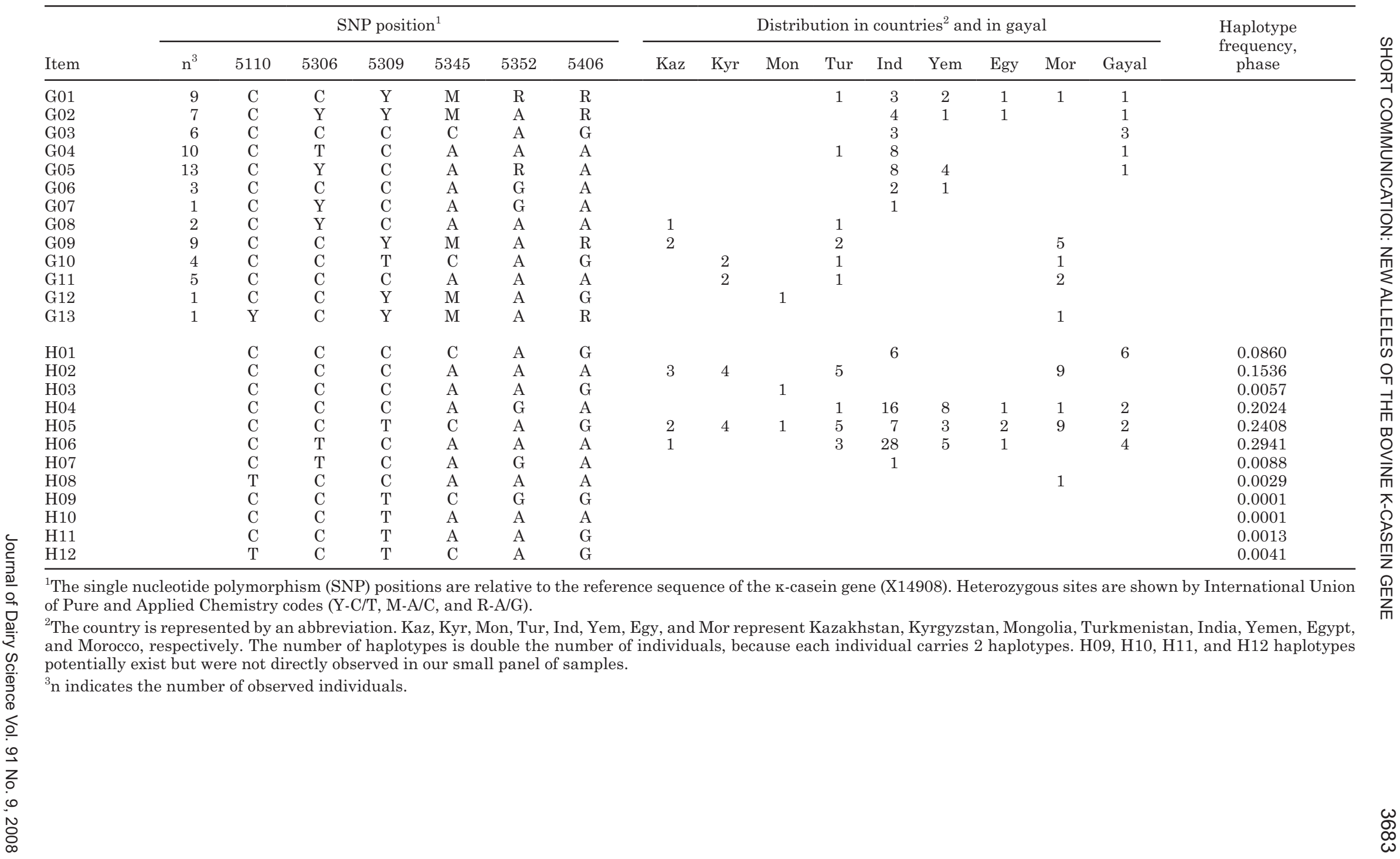




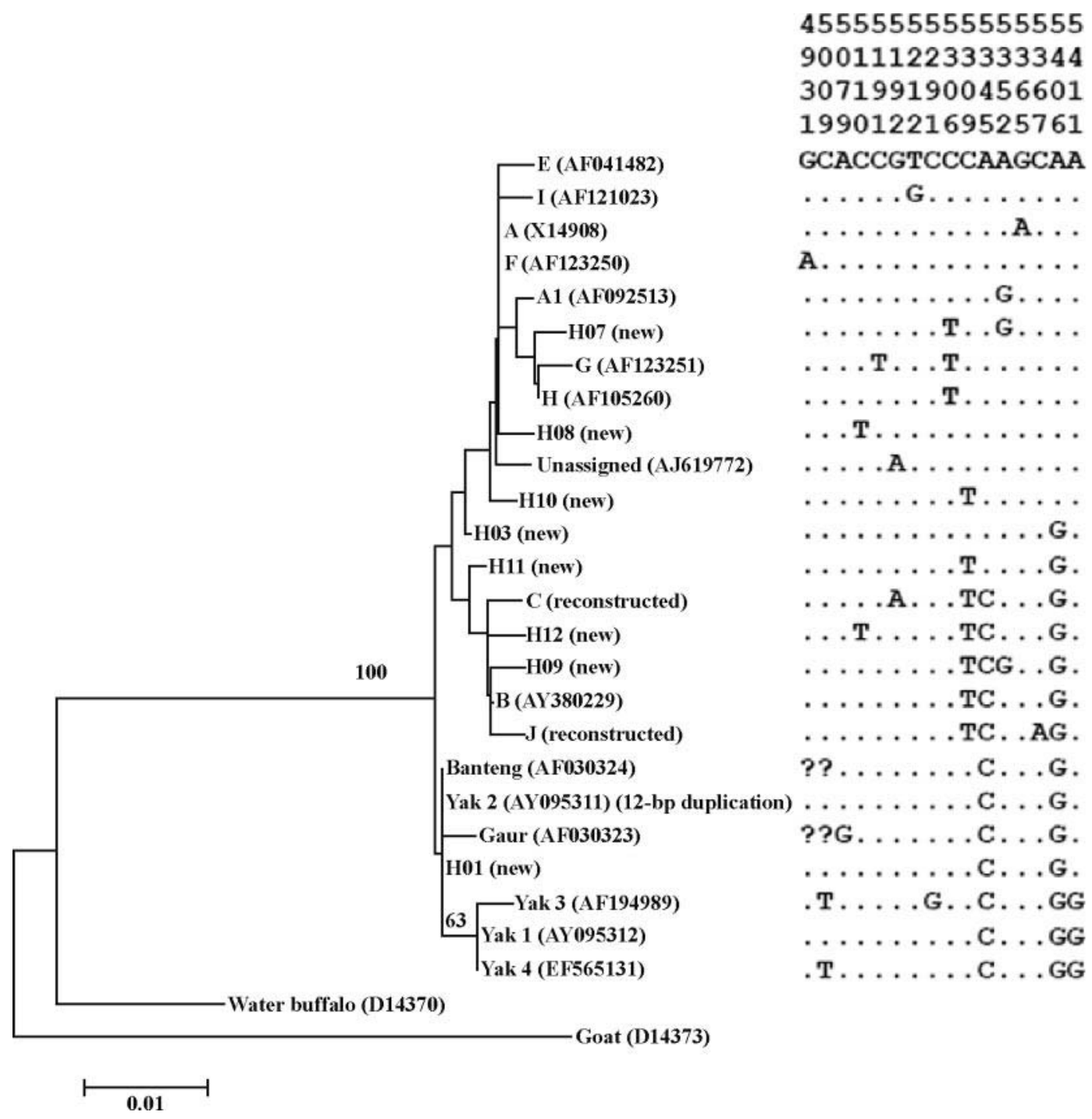

Figure 1. Neighbor-joining tree of new haplotype sequences, known cattle CSN3 alleles, and sequences from the yak, banteng (AF030324), and gaur (AF030323). The water buffalo (D14370) and goat (D14373) were used as outgroups. Cattle $C S N 3^{*} C$ and $C S N 3^{*} J$ were reconstructed following the method of Prinzenberg et al. (2008). Because of ambiguity of alignment, the 12-bp duplication in the yak sequence (AY095311) was not considered, and this made it the same as our new haplotype H01. Numbers above the nodes indicate bootstrap values from 1,000 bootstrap replications (only values $>50$ are shown).

genetic diversity at the CSN3 (as well as in the other milk protein and functional genes) in cattle from Asia to have a more accurate worldwide estimation of the genetic diversity patterns for this gene.

Because very few molecular-based data exist on the genetic origin of cattle from Central and South Asia, it is important first to use a more efficient approach to detect new variants in the CSN3 gene. For that task, resequencing of the entire exon IV, which harbors all the functionally important mutations, is highly recommended. Indeed, technological advances have contributed to a significant reduction of the resequencing cost; therefore, resequencing has become an affordable alternative to other techniques such as PCR-single strand conformation polymorphism.

The aim of this study was to use resequencing to search for new CSN3 alleles in a panel of native Asian and Northern African cattle. Because limited information exists on the genetic diversity in this gene for other species in the Bos genus, we also sequenced samples from the supposed Zebu $\times$ gaur (Bos gaurus) hybrid, the gayal (Bos frontalis).

Tissue samples were collected from local cattle in Kazakhstan (B. taurus, $\mathrm{n}=3)$, Kyrgyzstan $(B$. taurus, $\mathrm{n}=4)$, Mongolia (B. taurus, $\mathrm{n}=1)$, Turkmenistan $(B$. taurus $\times B$. indicus, $\mathrm{n}=7)$, India $(B$. indicus, $\mathrm{n}=29)$, 
Yemen (B. indicus, $\mathrm{n}=8)$, Egypt (B. taurus, $\mathrm{n}=2)$, and Morocco (B. taurus, $\mathrm{n}=10)$. In addition, 7 samples from Myanmar gayal (B. frontalis) were included in this study. Because most of the countries in Central and Southern Asia represent a contact zone between taurine- and indicine-like cattle (Felius, 1995), some individual samples from Kazakhstan, Kyrgyzstan, Yemen, and Turkmenistan, might in fact be crosses between $B$. taurus and B. indicus. Therefore, we expected to observe sequence variants originating in both the taurine and indicine lineages. Efforts were made to avoid sampling related individuals. We sampled only from small remote villages and excluded research centers, large cities, and coastal harbors where recent international shipping of cattle was possible. Genomic DNA was extracted by a DNeasy Blood and Tissue Kit (Qiagen, Valencia, CA).

The CSN3 exon IV was PCR amplified by using primers ExIV\#1 and 551\#2 (Prinzenberg et al., 1999). Polymerase chain reactions were performed in a $20-\mu \mathrm{L}$ volume containing $1 \times \mathrm{PCR}$ buffer, $2.5 \mathrm{mM} \mathrm{MgCl} 2,0.2$ $\mathrm{m} M$ deoxynucleotide 5 '-triphosphates, $0.4 \mu M$ each primer, $0.6 \mathrm{U}$ of AmpliTaq Gold DNA Polymerase (Applied Biosystems, Foster City, CA), and approximately $30 \mathrm{ng}$ of genomic DNA. The PCR mixture underwent $10 \mathrm{~min}$ at $95^{\circ} \mathrm{C}, 40$ cycles of $30 \mathrm{~s}$ at $95^{\circ} \mathrm{C}, 30 \mathrm{~s}$ at $52^{\circ} \mathrm{C}$, $45 \mathrm{~s}$ at $72^{\circ} \mathrm{C}$, and a final $5 \mathrm{~min}$ at $72^{\circ} \mathrm{C}$ on a GeneAmp PCR System 9700 (Applied Biosystems). Polymerase chain reaction products were purified and sequenced in the High-Throughput Genomics Unit, Department of Genome Sciences, University of Washington. Sequence trace files were checked and aligned by using DNAStar 6.0 (DNAStar Inc., Madison, WI). All new haplotype sequences were submitted to GenBank (accession numbers EU595506 to 595513).

A Bayesian model-based algorithm (Phase 2.1; Stephens et al., 2001; Stephens and Scheet, 2005) permitted us to infer haplotypes with a high confidence level (probability 0.97 to 1.00) from unphased genotypes and to estimate their frequencies. Several independent runs were performed to check the consistency between different runs. A neighbor-joining tree of newly inferred haplotypes and known bovine CSN3 alleles was constructed under uncorrected $p$ distance by using MEGA4 (Tamura et al., 2007).

In our small panel of samples, 13 different genotypes were defined by 6 SNP, including 5 phase-known genotypes (G03, G04, G06, G10, and G11) and 8 unphased genotypes (Table 1). Notably, 5 genotypes (G01 to G05) are shared by gayal samples and domestic cattle. From these 13 genotypes, 12 haplotypes (Table 1) were reconstructed and their frequencies were estimated. Among the 12 haplotypes, H02, H04, H05, and H06 corresponded to the known cattle alleles $\operatorname{CSN}^{*} A$,
$\operatorname{CSN}^{*} A^{1}, \operatorname{CSN}^{*} B$, and $C S N 3^{*} H$, respectively. The new haplotypes, $\mathrm{H} 08$ and $\mathrm{H} 10$, differed from $C S N 3^{*} A$ by one nonsynonymous mutation (T5110C-Ser70Pro and T5309C-Ile136Thr), whereas the new haplotypes $\mathrm{H} 01, \mathrm{H} 11$, and $\mathrm{H} 12$ were differentiated from $C S N 3^{*} B$ by one nonsynonymous mutation (T5309C-Ile136Thr, A5345C-Ala148Asp, and T5110C-Ser70Pro). Finally, the new haplotypes H03, H07, and H09 were different by one silent mutation from $\mathrm{CSN}^{*} \mathrm{~A}, \mathrm{CSN}^{*} \mathrm{H}$, and $C S N 3^{*} B$, respectively (Table 1 ). Interestingly, H01 was observed in 3 gayal and 3 Zebu individuals (Table 1) and had a close phylogenetic relationship with the banteng (Bos javanicus), gaur, and yak (Figure 1). Our results support the hypothesis that genetic diversity in exon IV of CSN3 has been underestimated in domestic cattle; it also highlights the urgent need to resequence functionally important genes in locally adapted cattle populations. This study shows the advantages of reporting the haplotypes instead of single sequences. Notably, a search in GenBank for the number of unique sequences (haplotypes) from cattle CSN3 exon IV returned only 9 different haplotypes (representing 7 polymorphic sites). This demonstrates that genetic diversity is highly underestimated, because this study alone contributed 8 new haplotypes.

The haplotype information will help us to understand the evolution of this gene as well as the consequences of different combinations of amino acid changes in the protein structure and function. In fact, this short survey (71 individuals) was enough to identify a new nonsynonymous SNP and several new haplotypes absent so far from previously reported commercial cattle breeds (e.g., Prinzenberg et al., 1999). Thus, our study provides a simple but clear example of how important it is to define diversity in the context of livestock genetic resources by using sensitive resequencing techniques and worldwide samples from local breeds and related species.

\section{ACKNOWLEDGMENTS}

This work was funded by Fundação para a Ciência e Tecnologia (FCT) project POCI/CVT/56758/2004. SYC and AB-P are supported by FCT grants SFRH/ BPD/26802/2006 and SFRH/BPD/17822/2004, respectively. GL was supported by the Portuguese-American Foundation for Development, CIBIO, and Universidade do Porto.

\section{REFERENCES}

Bai, W. L., R. H. Yin, S. J. Zhao, Y. C. Zheng, J. C. Zhong, and Z. H. Zhao. 2008. Characterization of a k-casein genetic variant in the Chinese yak, Bos grunniens. J. Dairy Sci. 91:1204-1208. 
Dziuba, J., and P. Minkiewicz. 1996. Influence of glycosylation on micelle-stabilizing ability and biological properties of C-terminal fragments of cow's K-casein. Int. Dairy J. 6:1017-1044.

Food and Agriculture Organization of the United Nations. 2007. The State of the World's Animal Genetic Resources for Food and Agriculture. B. Rischkowsky and D. Pilling, ed. FAO, Rome, Italy.

Felius, M. 1995. Cattle Breeds-An Encyclopedia. Misset Uitgeverij, Doetinchem, the Netherlands.

Jaeckel, S., J. T. Epplen, M. Kauth, B. Miterski, F. Tschentscher, and C. Epplen. 1998. Polymerase chain reaction-single strand conformation polymorphism or how to detect reliably and efficiently each sequence variation in many samples and many genes. Electrophoresis 19:3055-3061.

Matin, M. A., and H. Otani. 2002. Cytotoxic and antibacterial activities of chemically synthesized $\mathrm{k}$-casecidin and its partial peptide fragments. J. Dairy Res. 69:329-334.

Mitra, A., P. Schlee, I. Krause, J. Blusch, T. Werner, C. R. Balakrishnan, and F. Pirchner. 1998. k-Casein polymorphisms in Indian dairy cattle and buffalo: A new genetic variant in buffalo. Anim. Biotechnol. 9:81-87.

Ng-Kwai-Hang, K. F., J. F. Hayes, J. E. Moxley, and H. G. Monardes. 1984. Association of genetic variants of casein and milk serum proteins with milk, fat, and protein production by dairy cattle. J. Dairy Sci. 67:835-840.
Prinzenberg, E. M., H. Jianlin, and G. Erhardt. 2008. Genetic variation in the $\mathrm{k}$-casein gene (CSN3) of Chinese yak (Bos grunniens) and phylogenetic analysis of CSN3 sequences in the genus Bos. J. Dairy Sci. 91:1198-1203.

Prinzenberg, E. M., I. Krause, and G. Erhardt. 1999. SSCP analysis at the bovine CSN3 locus discriminates six alleles corresponding to known protein variants $(A, B, C, E, F, G)$ and three new DNA polymorphisms $\left(H, I, A^{1}\right)$. Anim. Biotechnol. 10:49-62.

Sheffield, V. C., J. S. Beck, A. E. Kwitek, D. W. Sandstrom, and E. M. Stone. 1993. The sensitivity of single-strand conformation polymorphism analysis for the detection of single base substitutions. Genomics 16:325-332.

Stephens, M., and P. Scheet. 2005. Accounting for decay of linkage disequilibrium in haplotype inference and missing-data imputation. Am. J. Hum. Genet. 76:449-462.

Stephens, M., N. J. Smith, and P. Donnelly. 2001. A new statistical method for haplotype reconstruction from population data. Am J. Hum. Genet. 68:978-989.

Tamura, K., J. Dudley, M. Nei, and S. Kumar. 2007. MEGA4: Molecular Evolutionary Genetics Analysis (MEGA) software version 4.0. Mol. Biol. Evol. 24:1596-1599.

Yvon, M., S. Beucher, P. Guilloteau, I. L. Huerou-Luron, and T. Corring. 1994. Effects of caseinomacropeptide (CMP) on digestion regulation. Reprod. Nutr. Dev. 34:527-537. 